\title{
Scenario Planning for the Edinburgh City Region
}

lain Docherty [1] ${ }^{*}$ and Peter McKiernan [2]

[1]

Department of Management

University of Glasgow

Glasgow

G12 8QQ

Scotland, UK

[2]

School of Management

University of St Andrews

The Gateway, North Haugh

St Andrews

Fife

KY16 9SS

Scotland, UK

* corresponding author 


\title{
Scenario Planning for the Edinburgh City Region
}

\begin{abstract}
This paper examines the application of scenario planning techniques to the detailed and daunting challenge of city re-positioning when policy makers are faced with a heavy history and a complex future context. It reviews a process of scenario planning undertaken in the Edinburgh city region, exploring the scenario process and its contribution to strategies and policies for city repositioning. Strongly rooted in the recent literature on urban and regional economic development, the text outlines how key individuals and organisations involved in the process participated in far-reaching analyses of the possible future worlds in which the Edinburgh city region might find itself.
\end{abstract}




\section{Scenario Planning for the Edinburgh City Region}

\section{Introduction}

This paper examines how city stakeholders can harness the power of a scenario development process to help re-position their city over the long term and within a changing and challenging environmental context. It uses the experience of the Edinburgh city region in Scotland as a case history to illustrate the process. The first section reviews the transition of cites beyond the de-industrialisation phase to become the new engines of economic growth as the centres of vibrant metropolitan regions. The text then goes on to explore the successful governance and network structures that help generate strategic capacity in cities. The focus then turns to Edinburgh, its development trajectory and the use of scenario planning to help re-position the city in challenging future terrain. The concluding section reflects upon Edinburgh's experience and offers lessons for policy on future city prospecting.

\section{Cities: back from the brink}

After several decades in which they have been widely perceived as ailing places characterised by economic and social stagnation and/or decline, many large cities are searching for innovative, more effective ways to achieve and maintain competitive advantage in a globalising economy (Boddy and Parkinson, 2004; Gordon and Buck, 2005). The shift to the 'new' or 'knowledge' economy has in large part driven this transformation, with cities once again perceived as engines of regional and national economic growth (Sim et al, 2003). Cities able to capitalise on historically-strong knowledge sectors, such as higher education, administration and business services, appear well placed to build high value, knowledge-intensive economies in this new 
environment (Kresl, 1995; Begg, 2001; Park, 2002). Those that offer the combination of this knowledge-driven growth with a liberal, tolerant attitude to lifestyle choice are even argued by some to represent the key growth poles of the future (Florida, 2004).

The contemporary emphasis on the agglomeration of knowledge exchange between companies, research centres and key individuals as the generator of innovation and growth in the $21^{\text {st }}$ century implies that the importance of the spatial organisation of the economy should be re-evaluated (Liebovitz, 2004; Simmie, 2004; Bailey and French, 2005). Combined with the increasing importance of the cultural and consumption identities of place in supporting competitiveness, this means that cities have again become a critical arena for research into economic development (Gordon and McCann, 2000; Savitch and Kantor, 2004). The so-called "new economic geography" has been at the forefront of this movement, prompting a debate about the "best" scale for organising economic policy intervention (Wannop, 1995; OECD, 2002). The outcome of this process has thus far been a return to analysing the importance of regional economies, particularly city regions, in explaining national economic performance (Lever, 1999; Wood and Parr, 2005). Given the increasing prominence of the largest 'world cities', those relatively peripheral places, such as Edinburgh, can find it doubly hard to compete in globalising markets dominated by the largest urban agglomerations (Löfgren, 2000).

Of further interest are those cities - also including Edinburgh - that have avoided (or overcome) the worst impacts of de-industrialisation to position themselves as genuinely competitive players in the new international marketplace (Cheshire and Carbonnaro, 1996; DiGaetano and Lawless, 1999). Although they are best placed to capitalise on the emerging knowledge economy, it can be very difficult even in these places to create and sustain a pro-growth political agenda - often described as a 'growth machine' - 
especially as they often have conservative political traditions and cultures. To be successful, policy networks and coalitions need to be highly adept at managing the consequences of growth as well as generating growth in the first instance, so that that the impacts of economic expansion are seen as manageable by-products of success, rather than as reasons to turn the growth tap off altogether (Troutman, 2004).

In recent decades, intensified urban economic competition, particularly for inward investment, has prompted many cities to focus their strategies on improving the attractiveness of the different 'bundles' of assets that they offer (Docherty et al, 2004). Traditionally, most attention has been focused at the bundles of physical assets, which include land, industrial and commercial property, transport infrastructure and so on. In the last 20 years, many policies and strategies have focused in improving the bundles of 'human capital', that is the knowledge assets from general workforce skills to the number of specialised service companies (Begg, 2001). Such policies have been designed to improve the links between universities, research institutions and firms have also been applied in an attempt to position cities at the centre of 'learning regions' with substantial potential for product and process innovation (Cooke and Morgan, 1998; Glaeser, 1999; Lever, 2001).

More recently, many cities have focused on improving their bundle of organisational assets by promoting public policies focused around notions of 'good governance'. A number of terms have been used to describe the concept of good governance, which can usefully be translated (in economic development terms) as the ability of cities and their institutions to generate and sustain the conditions for improved competitiveness. The most often used term is "strategic capacity", which refers to the potential of the system of governance and administration to solve problems - and maximise 
opportunities - as they arise (van den Berg et al, 1997; Albrechts, 2004). The depth, extent and quality of cross-sectoral networks can be a particularly important determinant of city competitiveness, since these kinds of networks are often crucial in providing the political leadership necessary to shape strategies and influence key government policies to the advantage of the city and its region (Pierre, 1999; Boddy and Parkinson, 2004). In addition, since it is by definition an integrating concept, the idea of the city region is also proving increasingly attractive to those interests inside cities keen to provide a more coherent and effective basis for articulating how the modern economy operates across formal administrative boundaries (Perkmann, 2007).

\section{New management and governance in cities - generating strategic capacity}

Until relatively recently, remarkably little attention was paid to the impact of governance and policy networks at the regional level, and how they influenced the ability of city regions to innovate and adopt progressive policies for competitiveness through generating genuine strategic capacity. However, over the last 5-10 years, a great deal of research has been done that suggests the ability to innovate at a local level by sharing information effectively between local stakeholders - including small firms and the corporate and public sectors - is vitally important (Buck et al, 2005; OECD, 2007). This is because both the structure and capabilities of organisations, and the level of local innovation and flexibility in policy matters, are argued to very strongly influence the levels of economic success cities achieve.

Central to the notion of generating improved strategic capacity is the task of developing the conditions for greater private sector and public participation in decision making, more effective, flexible multi-agency working, and greater "institutional thickness" (Raco, 1999; Turok, 2000; Bailey et al, 2001). Improving the quality and capacity of urban political 
leadership can be a vital component of this process, contributing the confidence, vision and dynamism required to secure a consensus for the strategies required to reposition the city in the global economy (John and Cole, 1999; Kleinman, 2002).

Creating this depth of networking and commitment is not easy, since there is a recurring dilemma for politicians torn between maintaining their traditional power bases in local political movements and party structures on the one hand, and their desire to maximise the impact of their policies by allying with other sectoral interests, such as the business community, on the other. Following the influential work of Francis Fukuyama, the concept of trust has been highlighted as important in this respect, with no little effort required of the representatives of the various interests brought together in thick networks to overcome inherited suspicion and cultural differences if genuinely cohesive policy making is to emerge (Fukuyama, 1995; Huxham and Vangen, 2000; Healey, 2002).

The celebrated political sociologist, Robert Puttnam, advances this analysis to highlight one essential pre-requisite for such conditions to come about - a culture of political pragmatism in city politics that transcends traditional sectoral interests (Puttnam, 2002). In turn, for this to be achieved, it is crucial that the city benefits from clear and far-sighted political leadership, so that an adaptive culture of cooperation and joint working can be created. Such visions can he helped through the deployment of proven foresightful techniques like scenario planning.

\section{The evolution of scenario planning techniques}

Scenario planning is a process that combines stories and/or images of plausible future environmental contexts with the practical means of adapting to these possible futures today. The history of the technique is rooted in US military planning during WWII and the 
post war rebuilding of Europe, especially France, with the RAND Corporation established in 1945 as a conduit for applied futures research in the uncertain post-war environment. By the 1950s, its 'systems theory' approach was extended from defence studies into social issues like urban decay and resilient poverty. One of its most influential thinkers - Herman Kahn - left after a few years to set up the Hudson Institute in 1961, where his 'foresight' studies speculated on the 'World of 2000'. Kahn's future conjectures were based primarily upon the analysis and forward projection of long term trends such as population growth, and their impact at key stages in societal development. He applied the term 'scenarios' - already used in Hollywood to describe the narrative of a motion picture ${ }^{1}$ - for the resultant future landscapes, defining a scenario as

"A hypothetical sequence of events for the purpose of focusing attention on causal processes and decision points.“

Kahn (1965).

The Hudson research attracted the interest of a variety of multi national companies including Corning, IBM and Shell. The Shell Corporation is widely credited with the first commercial applications of Kahn-based scenario planning. In 1965, Shell had introduced its global 'Unified Panning Machinery' that described, in great detail, the process that oil followed from extraction all the way to the retail petrol outlet. However, the forecasting-

\footnotetext{
${ }^{1}$ Well aware of this parallel, Kahn stressed non-fictional films in his analogy, as these were the basis for the imaginative stories he had in mind for describing possible futures. Ironically, in 'thinking the unthinkable' about thermonuclear warfare, the Dr Strangelove character in Stanley Kubrick's 1963 film of the same name was in fact based on Kahn.
} 
based UPM technique began to struggle when faced with the increasingly uncertain price of crude oil and the potential availability of alternative fuels. So, in 1969, Shell experimented with different approaches to looking at its business future over a 15-year planning horizon. Pierre Wack, working for Shell Français, capitalised on Kahn's work and introduced qualitative scenario stories into the planning process as a better way of thinking about the future than probabilistic forecasting based upon past trends. Early scenario planning at Shell ran alongside the more traditional UPM on an experimental basis for several years.

In these pioneering times, Wack questioned Shell's dominant thinking - that oil supplies were secure and resources plentiful - largely because the major oil companies were in control, asking what might happen if control were ceded to the producing nations. His team developed a crisis scenario premised upon the producers taking power and restricting supply. When this hitherto unthinkable outcome transpired to trigger the fourfold increase in the oil price and subsequent energy crisis of 1973 , the scenario approach quickly gained credence. Planners, faced with increasing complexity in their external contexts, had to embrace uncertainty rather than predictability and the new scenario planning technique provided the requisite tools through its combination of imagination, qualitative analysis and challenging narrative.

In post-war Europe, scenario planning emerged from the need to galvanise society and re-create cultures and economies from the grassroots. In France, Gaston Berger founded the 'Centre d'Etudes Prospectives' (CEP), where he developed a scenario approach to long range planning entitled 'La Prospective'. Berger believed that the future was not predetermined, but rather something that could be shaped to the benefits of wider society by emphasising positive future scenarios. By the 1960s, this approach had 
embraced education, the environment, urbanisation and regional planning, with Pierre Masse (the Commissioner for the French National Plan) incorporating the approach into the 4th French National Plan (1960-1965). Subsequent iterations of the CEP methodology focused on influencing key political groups and specifying ways in which these futures could improve the lives of ordinary people (de Jouvenal, 1967), and the development of fresh tools and techniques, including pioneering computer simulation, after the arrival of defence analyst Michel Godet in the 1970s.

These scenario approaches are useful on several levels, since they: provide assistance in making sense of complex contexts enabling early strategy preparation; rehearse the potential impacts of structural and 'unknowable' variables; perform judicial duties in due diligence situations; aid flexible deployment of resources; prevent cognitive freezing on particular ways of doing things; unify teams around common goals; stretch collective ambition; generate new ideas and innovations and help solve seemingly intractable problems between fractious groupings in a politically and philosophically 'neutral' space. However, perhaps the greatest contribution of scenario planning lies in its active engagement of actors in its process and its power to enable them to think about complexity and uncertainty in external contexts, and then how they might shape the external environment to contribute to their own strategic ends.

\section{Applying scenarios to cities}

Genuine city repositioning is a generational affair requiring foresight over the long term (Meijer, 1993). Scenario planning, being a qualitative technique of strong narrative, has become a critical planning tool for analysis of deep futures in the public sector with countries, regions and cities embracing its creative approach to how worlds might evolve. Thus, the technique's application to city planning is entirely consistent with the 
description of the Shell etc interpretation of scenario planning as a "strategic conversation" into possible futures (Van der Heijden, 1996).

The emergence of scenario planning as a key tool in urban revitalisation reflects both the complex contexts faced by policy makers, and the weaknesses of traditional planning techniques like forecasting and budgetary analysis, which can act as a straightjacket, strangulating creative thinking and innovative policies. The shift to knowledge intensive, service economies coupled with supply and demand side globalisation, changing demographics, growing concerns over energy security, climate change and the 'real time' expectations from an educated consumer base create an interaction of variables whose complexity exhausts the design potential of ordinary tools (Hertel, 2006). Analysis of such contexts requires the development of a real narrative articulating the depth of this change in itself a critical part of the process (Beauregard, 1993).

Fortunately, scenario planning thrives under these conditions. Customised and facilitated carefully, it has three direct uses for city development. First, it can be used to influence social or political affairs and develop quality information for public consumption e.g., scenarios for the future of city regions, for city centre streetscapes, for deprived regions within cities, for the future of the city's cultural development or for its transportation system. Here, new ideas can be generated and communicated to a large audience and these ideas can be set, and tested, against a series of possible future contexts. Second, it can be developed for strategic decision support within city planning units, such as in the rehearsal of critical decisions against a series of potential outcomes, in assisting strategy formulation through a thorough environmental analysis, and perhaps more importantly, in developing a series of alternative futures for the city for which strategies 
and policies can be developed to take full advantage of opportunities presented or a full defence against threats exposed.

Finally, scenarios can be used for learning and development across city organisations essentially to generate and sustain strategic capacity - by including many and various voices to generate the knowledge, information and creative ideas necessary to build the strategic capacity required to distribute 'ownership' of the output across the diversity of groups in the city (Harding, 1997; Leo, 1998).

However, to achieve these ends, careful application is required as the appropriate scenario planning method must be tailored to the local economic, political and institutional context. Scenarios can be defined by their architecture, their content or by the methodology used to develop them (Martelli, 1996). Perhaps the most frequently used scenario "architectures" are explorative scenarios that trace key trends from the past, through the present and into the future, such as demographics and economic shiftshare analysis. Such scenarios illustrate the future consequences of these pathways, identifying the signposts that flag key decision points on each pathway so that future positions can be known and the effect of specific policies can be measured.

These scenarios are relatively easy to develop if data is available on past trends and intelligence can be gathered on their likely trajectory; indeed if uncontroversial these data are often said to represent the 'natural agenda'. Alternatively, scenarios can be built from the future back to the present. These are called 'anticipatory' scenarios, and work by identifying a key future event with a significant impact such as the staging of the Olympics or other major sporting or cultural event, and then work the pathway back to 
the present by asking the simple yet insightful question, "how did this key event come about?'

Sometimes when past and current data is not widely available e.g. in the presence of new technologies, or when the complex interaction of many key variables makes extrapolation futile such as in the deep future studies of complex economies, normative scenarios can be used. These scenarios are built around a key indicator and allow the indicator to drive other events: a typical question might be, "what would a city look like if its economy were to sustain 3\% annualised GDP growth over a 15-year period?" In combination, the impact of various potential growth rates can be translated to a set of real budgetary allocations to policies in the present and these effects analysed.

However, none of this is to say that scenario planning is without limitations. The narrative output of scenarios is identifiably weaker than that of forecasting methodologies in the short term. Moreover, it is difficult to root in organisations where numbers are the prime component in executive thinking to the extent that qualitative techniques are regarded with real suspicion or even excluded altogether. Scenarios can also be weak when survival tactics are required in response to immediate crises dominating the policy agenda. At the extreme, there can be prohibitive cognitive resistance to the very notion of the scenario planning process itself, especially where the exploration of difficult issues raises matters of political or personal sensitivity, such as when individual or institutional pride, or pet projects are challenged. However, for cities searching for a longer term vision, accompanied by robust and creative policies, and as a means to develop the kinds of 'institutional thickness' in terms of stakeholder involvement that reflects good governance, the process represents a significant addition to ordinary planning toolboxes. In particular, where cities have an abundance of 
atomistic policies and strategies, developed in unconnected silos and running parallel to each other with different time-frames, a scenario process can weave such projects together into a common future view without losing individual ownership rights. The process is not a panacea but does often represent significant strategic progress.

\section{Edinburgh's development trajectory}

Although Edinburgh's recent economic performance has been strong by Scottish and UK standards, there remain significant question marks over its real level of competitiveness when set against equivalent cities in Europe and further afield. Spurred on by devolution, Edinburgh has been one of the fastest growing parts of the Scottish economy, consolidating its position at the heart of Scotland's knowledge economy over the last decade (BAK Basel Economics, 2006).

Comparisons with other UK 'Core Cities' highlight the generally strong economic performance of Edinburgh in recent years, as the city moves to position itself as a genuinely innovative location of the kind that competes successfully in international markets (Charles et al, 1999; Simmie, 2004). Several policy interventions have been key to this, including the planned, phased release of substantial tracts of development land, the formation of innovative special purpose vehicles for the delivery of economic development projects, and a renewed focus on the quality of the physical environment of critical locations, most notably the UNESCO World Heritage Site of the city centre.

Like many cities in continental Europe, Edinburgh has fared better over recent years than the national economy in which it is located, with the city's economic growth continuing to outpace both Scotland and the UK. In the 5 year period to 2003, Edinburgh's annualised economic growth rate was the highest of all UK comparator 
cities (Oxford Economic Forecasting, 2004). Recent statistics suggest that this performance has made Edinburgh the best performing local economy in the UK on some measures (HM Treasury, 2006). Although increased competition from other cities in the UK elsewhere, such as the last wave of EU succession states, will make this performance harder to sustain in future.

\section{$<$ Table 1 here $>$}

Although Edinburgh is now the strongest major city in the UK outside London economically, it still lags considerably behind its major European competitors in terms of wealth creation, the current rate of growth and scientific innovation (Parkinson et al, 2004; BAK Basel Economics 2006). Indeed, it is recognition of this international performance gap - and the potential fragility of some of the city's currently high performing sectors - that prompted the city's leaders to engage in a scenarios process in the first place.

\section{< Figure 1 here >}

The scenarios process was informed by several preceding studies analysing these strategic conditions and the policy contexts arising from them. One particularly important example - which helped crystallise the debate about Edinburgh's relative performance when compared to other successful city regions - concerned the city's impact in terms of key knowledge economy activity. Despite its high skills levels, internationally-renowned higher education institutions and substantial investment in biotechnology and other cutting edge science disciplines, Edinburgh's performance in terms of high knowledge content economic activity remained relatively modest (Local Futures Group, 2004). 


\section{$<$ Figure 2 here $>$}

More widely, the Edinburgh of the year 2000 had several strategic plans largely operating in isolation from one other, ranging from those designed to protect the World Heritage Site streetscapes to medium term social, health, planning and transport strategies covering the city (and often its wider region) as a whole. Although the evidence confirmed the city was one of (if not the) key engine(s) of the otherwise relatively modestly growing Scottish economy, and there was a general acceptance that, if it stuttered, the national economy would likely follow quickly. There was no guarantee that headquarters and high value activities would continue to be anchored in the city over the longer term. Rapidly rising house prices were a double edged sword; although many people in the city benefited, others could no longer afford property, and much of the value was exported to speculators and developers seeking to spread their portfolios in a time of reduced returns from the London market (Smith and Ford, 2002). Gridlock had gripped the historic core of the city, with proposals for a congestion charge, after London's example, exciting heated debate (McQuaid and Grieco, 2005). Finally, although the tourist sector remained strong, helped in large part by this renewed global presence and strong growth of the city's airport, urban deprivation remained entrenched in some of the city's notorious housing estates.

\section{Creating Scenarios for Edinburgh}

By the spring of 2001, Edinburgh's city strategists faced major decisions on the future direction of their city's economic progress. The need to better understand the pressing issues facing the city region's economy arose out of a number of meetings across the region's governing networks, focused on the City Development department, which 
(unusually for a British local authority) brought together economic development, planning and transport functions under one roof. These discussions were triggered by various independent discussions on the implications of the various sectoral strategies identified above, the critically important response to the Royal Bank of Scotland's decision on whether to develop their world headquarters in the city, and the integrative process of developing the joint Structure Plan for the city region. This, and other Council-led processes, highlighted three critical challenges facing the city in the medium to long term: transport, labour supply and property/accommodation (especially private housing).

The consultation programme engendered a widespread desire across the city region's key partners for positive action to investigate these challenges head on. As a result, the Council agreed that a scenario planning exercise should be commissioned to a) add intellectual value and robustness to the underlying analysis informing the Structure Plan; b) to generate an inspirational vision for the city that was plausible and achievable and owned by many to enhance strategic capacity; c) to engage with a variety of stakeholders on economic development and so stimulate inclusiveness and policy alignment; d) to facilitate a strategic conversation on future pathways and map those pathways in detail so that strategists could monitor their future positions and take action where and when appropriate; e) to help revise the economic development strategy; f) to inform the policies of the city's key agencies and g) to add significant new data to the city's wider knowledge base.

After initial debates between these groups and the research team - who have pioneered the application of scenario methodologies in the public and private sectors for over two decades (see, for example, McKiernan et al, 2001 and MacKay and McKiernan, 2004) - 
the scenario process was customised to the City's specifications and the following brief issued:

"The scenario process will explore how the Edinburgh City Region (ECR) might evolve over the next 20 years. In particular, what will be the critical uncertainties over this period? It is assumed that an in depth analysis of the main external drivers of change will be conducted and these should include: global, UK and Scottish economic performances, competition from other cities/regions, political developments both local and Scotland wide, demographics, taxation, expectations of citizens and society as a whole, environmental developments and technological advancement. The objective is to provide a visionary scenario to inform current policy."

The methodological process adopted to satisfy this brief was wideranging. Data gathering was based on extensive archival research, and one-to-one interviews conducted with over 100 significant individuals within and beyond the Edinburgh City Region, the sample carefully stratified sampling, to ensure that each main sector of the economy and society was covered appropriately. The parallel interview process utilised a semi-structured series of seven probing questions (Van der Heijden, 2002), selected to extract deep individual knowledge on a non-attributable basis. Interviewees were chosen for their knowledge and understanding of the key external factors and their impact or likely impact upon the ECR. They comprised of chief executives and senior managers of public and private sector organisations including inward investors, council leaders, policy advisors, journalists, elected politicians and public officials. These individual interviews were supplemented by six group interviews, which probed deeper for knowledge and 
context, capturing the richness of shared perspectives generated by good dialogue between individuals.

The resulting data from these 'triangulated' approaches was then applied to inform workshop sessions with key stakeholders and subject experts, asking 'This is what has been said - do you agree? What has been missed? Has anything changed?'. The outcome of this iterative process of discussion and debate was the identification of a list of commonly-agreed critical issues facing ECR over the next 20 years:

\section{$<$ Table 2 here >}

As scenarios embrace the uncertainty surrounding the evolution of main issues into the future, a process of uncertainty evaluation was conducted by the steering group leading to the following matrix, with the issues in the top right hand quadrant deemed to have the greatest impact and also the highest uncertainty of outcome for the Edinburgh City Region over the 20 year time horizon adopted by the scenarios process.

\section{$<$ Figure 3 here >}

A further set of workshops involving both the steering and advisory groups were then arranged to explore individual and interactive group understandings and perceptions of the themes emerging from phases 2 and 3, the creation of mutual trust between participants being an essential ingredient of the process allowing free and frank discussion of the challenges facing the city region and its performance to date in each area. The task of recording, interpreting and gauging these conversations was given to an individual who adopted the role of lead scenario writer, this person being an extremely highly regarded political and economic analyst. Following detailed 
discussions, two contrasting scenarios emerged and were written up in plain English into first draft format before being subject to a battery of tests for plausibility, internal consistency, surprise and challenge, relevance to the ECR and for completeness of narrative. After each of these 'wind tunnel tests', the scenarios were re-drafted until a final pair of texts had passed all the tests and was approved by the steering and advisory groups. The final scenarios traced two possible futures for the ECR over a 20 year period to circa 2025. 'Capital Gains' shows how the city could become the best location for quality of life in Northern Europe; 'Capital Punishment' illustrates how a longrun genteel decline could set in and condemn Edinburgh to a deeply problematic future.

\section{$<$ Figure 4 here >}

Following circulation of the draft scenarios, a final series of workshops was held in Spring 2005 to map the scenario outputs onto prevailing policy in a number of key areas for which the council and its local partners had lead responsibility. According to the scenarios, some critical choices had to be faced over the next decade, with each choice leading to different pathways and contributing to starkly distinctive futures:

- congestion charging: if implemented, traffic is actively managed and money is raised to fund a step change in public transport infrastructure and service quality; if not, roads - the economic arteries of the city - will continue to clog up, imposing significant costs on local firms and reducing the attractiveness of Edinburgh to commercial investors and tourists alike;

- public-private engagement: genuine, meaningful engagement between the public and private sectors through the new Business Assembly would lead to greater and 
more imaginative joint working that had previously been the case in the traditional PPP/PFI client/financier relationship which had often been characterised by wariness on both sides;

- leadership: deeper public-private engagement enriches the city and the region's collective leadership; in contrast, business disengagement will leave the city's political leadership isolated and create a political discourse characterised by conflict and partisan critique;

- networks: genuinely networked governance harnesses the potential of each stakeholder be they from business, politics or the third sector, with powerful individual leaders capable of emerging from any proactive organisation. Network governance enhances shared understanding of problems and facilitates the innovation in policy that signifies real strategic capacity and makes sustaining a growing city region possible; or, every interest group looks after itself in an atomistic manner and so the common good is downplayed or even ignored outright;

- voice for ECR: a sophisticated, networked political culture creates a single shared, articulated vision for the ECR, supported by many voices; or, because the ECR's voices are divided, the interests of the region are ignored by the Scottish Executive and key central government decisions influencing the future of the ECR are not to its advantage.

In each of the above cases, the first option from each pair is clearly the best choice with which to work towards the positive, aspirational future articulated in the Capital Gains scenario. The final phase of the ECR scenarios project is therefore the most powerful, 
yet the most difficult and long-lasting; the application of the outcomes of the scenarios, and the reaction to them, to build more effective policies and interventions across the range of responsibilities held by the city region's stakeholders.

\section{Lessons from Edinburgh}

\section{Refining the scenario methodology}

The Edinburgh project was one of the first, large-scale scenario projects targeted at city development in the UK. The tried and tested scenario process remained contextually robust and was able to harness other parallel projects within the city with good effect, such as the emerging Structure Plan. Further, its potential to engage fractious and opposing views in a neutral space around a common objective empowered its legitimacy among the steering group. However, several process refinements are suggested from its application at the city level. First, for scenarios to be impactful, both policy makers and receivers must respect them fully. On reflection, a more intensive use of Delphi groups ex ante would have led to a finer project specification in conjunction with the input from the technical steering group, and a greater and broader awareness of the delicacy of 'burning' issues at different layers of society. Second, the draft scenarios were debated at length within the technical steering group and refined accordingly. A simultaneous engagement and feedback from Delphi groups on these early drafts would have deepened the testing process and stimulated greater ownership on full publication. Finally, though the scenarios were well publicised in the media and spread across the city in a variety of communications, the dialogue on their policy impact was restricted to a small steering group. Hence, city people could have been left with an impression of yet another expensive planning exercise that had little impact on their lives.

\section{Pursuing the identified policy choices}


To date, pursuing the positive growth scenario has been difficult. Although there have been many positives - the establishment of an effective Business Assembly and comprehensive annual City Region Conference bringing together a very wide range of organizations to discuss the challenges facing the ECR are notable examples concerns remain over the city region's collective ability to grapple with the key issues facing Edinburgh remain real. These worries were amplified by the overwhelming rejection of the City of Edinburgh Council's plans for congestion charging in a public referendum in 2005. With this decision, the first of the critical choices outlined above, has not followed the positive trajectory suggested by the scenario process. Whether or not subsequent choices will be positive, and exactly how the scenarios themselves continue to inform the debate about the Edinburgh city region's future development, is the subject of ongoing research.

One of the main problems apparent in Edinburgh - consistent with its highly culturallyconservative approach to change and development - is the inherent appeal of the 'do nothing' option when the city is faced with critical decisions. In a parody of Puttnam's maxim that pragmatism in city politics is the key to success, Edinburgh's political posture - across all mainstream political parties - is becoming (even) more risk averse than before, in large part due to the inglorious failure of the congestion charging referendum, which is popularly seen as too 'brave', 'radical' or 'premature'. Thus there is an increasing gap between the professional value invested in the scenario planning process and the deeper understanding of potential futures generated by it, and the political reality of maintaining an uncontroversial status quo, even if this avoids essential actions and risks embedding long term genteel decline. 


\section{Conclusions}

This paper has examined how senior policy makers sought to articulate the process of strategic city re-positioning through the use of scenario planning, using the Edinburgh city region as a case history. Effective urban re-positioning and revitalisation requires bold strategic management capable of mobilizing the city's internal resources so that a range of policy themes and interventions can be aligned to achieve genuinely radical, positive change. Scenario planning can play an important role in generating debate over the different strategic futures open to the city, whilst at the same time preserving a politically neutral space in which contrasting views on the preferred course for public policy can be aired (Mietzner and Reger, 2005).

Specifically, the use of scenario planning techniques in city development has three advantages. First, as scenario processes explore phenomena from the past, through the present and into the future, they seek to identify the key drivers of change that policy makers must contend with. Better understandings of future environments can result simply from the strategic capacity generated by: the articulation of the shared experiences, hopes and fears that these experiences represent; the historical analysis of key trends and mapping these to the present; and the bringing together of a wide network of key stakeholders to participate actively in a foresight process.

Following a tight and focused schedule, actors develop a sense of 'shared ownership' of both inputs and outputs to the scenario process. Strategy that is "owned" by key actors has a much better chance of making a real contribution to operational effectiveness; all too often, strategies that are associated with particular interests or individuals fail since their designers act as atomistic agents pursuing their own circumscribed agenda. Moreover, the scenario process helps focus on a positive and common vision, while 
exposing participants to the penalties of straying into negative future worlds if things go wrong.

Further, the focus on a common long run vision counters the frequent trend for strategy to be a series of episodic short run engagements or interventions that eschew 'uncertainty' in favour of the 'known' ingredients of future domains. Such naïve approaches are often wrecked by trends or events that are not predictable (the so-called "unknown unknowns" as famously defined by Donald Rumsfeld, the former US Secretary of State for Defense). Finally, strategy making is enhanced as powerful actors combine resources synergistically and, with a common knowledge base, gain in confidence so as to influence the shape of their future domain rather than accepting it passively as a predesigned construct. Consequently, strategy is owned, designed to cope adaptively with shocks and enacted in a positive manner.

The Edinburgh story reflects this trajectory of problem identification, scenario construction and policy review. Subsequent review meetings and the three annual City Region Conferences held to date have tracked the relevance of the main scenarios, and they continue to reflect the choices facing those key decision makers framing the strategies and policies that will determine the future competitiveness of the city region. However, these successive milestones have also identified the scale of the challenge in mobilising and sustaining the common action required to move from scenario writing to the implementation of policies best placed to bring about the desired outcomes for the city region. However, no matter the value practitioners and other engaged stakeholders gain from this process, the power of political conservatism to constrain policy action should not be underestimated. 


\section{References}

Albrechts, L. (2004) "Strategic (spatial) planning re-examined", Environment and Planning B, 31 743-758.

Bailey, N. and French, S. (2005), 'The Locational Dynamics of Financial Services in Regional Cities', in Buck, N., lan Gordon, I., Alan Harding, A., Turok, I. (2005) (eds), Changing Cities: Rethinking Urban Competitiveness, Cohesion and Governance, Palgrave Macmillan, London.

Bailey, N., Docherty, I. and Turok, I. (2001), 'Dimensions of City Competitiveness: Edinburgh and Glasgow in a UK context', in Begg (2001), Urban Competitiveness: Policies for Dynamic cities, Policy Press, Bristol, 135-160.

BAK Basel Economics (2006) Edinburgh Economic Analysis and Benchmark Report, Scottish Enterprise, Edinburgh.

Beauregard, R. (1993), 'Representing urban decline - postwar cities as narrative objects', Urban Affairs Quarterly 29(2)187-202.

Begg, I. (2001) 'Investability': the Key to Competitive Regions and Cities?', Regional Studies 36(2)187-193.

Boddy. M. and Parkinson, M. (2004) City Matters: Competitiveness, cohesion and urban governance, The Policy Press, Bristol. 
Buck, N., Ian Gordon, I., Alan Harding, A., Turok, I. (2005) (eds), Changing Cities: Rethinking Urban Competitiveness, Cohesion and Governance, Palgrave Macmillan, London.

Charles, D., Bradley, D., Chatterton, P, Coombes, M. and Gillespie, A. (1999) Core Cities: Key Centres for Regeneration Synthesis Report, CURDS, University of Newcastle, Newcastle-upon-Tyne.

Cheshire, P. and Carbonaro, G. (1996) "Urban economic growth in Europe: testing theory and policy", Urban Studies 33(7) 1111-1128.

Cooke, P. and Morgan, K. (1998) The Associational Economy: Firms, Regions and Innovation, Oxford University Press, Oxford.

De Jouvenal, B. (1967) The Art of Conjecture, Basic Books, New York, NY.

DiGaetano, A. and Lawless, P. (1999) "Urban Governance and Industrial Decline: Governing structures and policy agendas in Birmingham and Sheffield, England, and Detroit, Michigan, 1980-1997", Urban Affairs Review, 34(4) 546-577.

Docherty, I., Gulliver, S. and Drake, P. (2004) 'Exploring The Potential Benefits of City Collaboration', Regional Studies, 38(4) 445-456.

Florida, R. (2004) The Rise of the Creative Class: And How It's Transforming Work, Leisure, Community and Everyday Life, Basic Books, New York, NY. 
Fukuyama, F. (1995) Trust. The Social Virtues and the Creation of Prosperity, The Free Press, New York.

Glaeser, E. L. (1999) 'Learning in Cities', Journal of Urban Economics September, 254277.

Gordon, I. and Buck, N. (2005), 'Cities in the New Conventional Wisdom', in Buck, N., Ian Gordon, I., Alan Harding, A., Turok, I. (2005) (eds), Changing Cities: Rethinking Urban Competitiveness, Cohesion and Governance, Palgrave Macmillan, London.

Gordon, I. R. and McCann, P. (2000) 'Industrial Clusters: Complexes, Agglomeration and/or Social Networks?', Urban Studies, 37(3) pp.513-532.

Harding, A. (1997) 'Urban Regimes in a Europe of the Cities?', European Urban and Regional Studies 4(4) pp.291-314.

Healey, P. (2002) "On Creating the 'City' as a Collective Resource", Urban Studies 39(10) $1777-1792$.

Hertel, G. (2006) 'Global Trends, Automotive Trends and Innovation Trends: A Perspective from a Global Company', proceedings of the $4^{\text {th }}$ International Scientific Conference: Challenges in Transport and Communications, University of Pardubice, Pardubice. 
HM Treasury (2006) Devolving decision making: 3 - Meeting the regional economic challenge: The importance of cities to regional growth, http://www.hmtreasury.gov.uk/media/20C/18/bud06 cities 563.pdf.

Huxham, C. and Vangen, S. (2000) 'Leadership in the Shaping and Implementation of Collaboration Agendas: How Things Happen in a (not quite) Joined Up World', Academy of Management Journal 43(6) pp.1159-1175.

John, P. and Cole, A. (1999) 'Political Leadership in the New Urban Governance: Britain and France Compared', Local Government Studies 25 (4) pp.98-115.

Kahn, H. (1965) On Escalation, Metaphor and Scenarios. Preager, New York, NY.

Kleinman, M. (2002) 'Steering, Rowing, Drowning or Waving? The New Governance of London', paper to ESRC Cities Conference, London, 29 May.

Kresl, P. (1995) "The determinants of urban competitiveness: a survey", in Kresl, P. and Gappert, G. (eds) North American Cities and the Global Economy, Sage, Thousand Oaks CA, 45-68.

Leo, C (1998) "Regional Growth Management Regime: the case of Portland, Oregon", Journal of Urban Affairs, 20(4) 363-394.

Lever, W. F. (1999) 'Competitive Cities in Europe', Urban Studies, 36 (5-6) 1029-1044. 
Lever, W. F. (2001) 'The Knowledge Base and the Competitive City', in Begg (2001), Urban Competitiveness: Policies for Dynamic cities, Policy Press, Bristol, 11-32.

Leibovitz, J. (2004), “Embryonic, knowledge-based clusters and cities: the case of biotechnology in Scotland", Urban Studies, 41 1133-1155.

Local Futures Group (2004) The Scottish Knowledge Economy, Scottish Enterprise, Glasgow.

Löfgren, A. (2000), "A thousand years of loneliness? Globalization from the perspective of a city in a European periphery" Geoforum, 31(4) 501-511.

MacKay, R.B. and McKiernan, P. (2005) 'Exploring Strategy Context with Foresight', European Management Review 1(1) 69-77.

McKiernan, P., Scott, A. and Davies, A. (2001) 'The High Road Scenarios for Scotland', Scenario and Strategy Planning 3(1) 22-26.

McQuaid, R. and Grieco, M. (2005) 'Edinburgh and the politics of congestion charging: Negotiating road user charging with affected publics', Transport Policy 12(5) 475-476.

Meijer. M. (1993) "Growth and decline of European cities: changing positions of cities in Europe", Urban Studies 30(6) 981-990. 
Mietzner, D. and Reger, G. (2005) 'Advantages and disadvantages of scenario approaches for strategic foresight', International Journal of Technology Intelligence and Planning, 1(2) $220-239$.

OECD (2002) OECD Synthesis Report: Glasgow's Urban Renaissance, OECD, Paris.

OECD (2007) Higher Education and Regions: Globally Competitive, Locally Engaged, OECD, Paris.

Oxford Economic Forecasting (2004) Data on Scottish economic performance, cited in Scottish Enterprise Edinburgh and Lothian (2005), Strategic Operating Plan 2005 2008, Scottish Enterprise, Edinburgh.

Park, S. O. (2002) 'Regional Innovation Strategies in the Knowledge-Based Economy', Geojournal 53(1) pp.29-38.

Perkmann, M. (2007) "Construction of New Territorial Scales: A Framework and Case Study of the EUREGIO Cross-border Region", Regional Studies, 41(2) 253 - 266.

Pierre, J. (1999) "Models of Urban Governance: the institutional dimension of urban politics", Urban Affairs Review, 34(3) 372-396.

Porter, M. and Ketels, C. (2004) UK Competitiveness: Moving to the Next Stage, framework paper to DTi and ESRC Cities Programme, http://www.isc.hbs.edu/econnatlcomp.htm. 
Putnam, R. D. (ed) (2002) Democracies in Flux: the Evolution of Social Capital in Contemporary Society, Oxford University Press, Oxford.

Raco, M. (1999) 'Competition, Collaboration and the New Industrial Districts: Examining the Institutional Turn in Local Economic Development', Urban Studies 36(5/6) 951-968.

Savitch, H. and Kantor, P. (2004) Cities in the International Marketplace: The Political Economy of Urban Development in North America and Western Europe, Princeton University Press, Princeton, NJ.

Sim, L-L, Ong, S-E, Agarwal, A., Parsa, A. and Keivani, R. (2003) "Singapore's competitiveness as a global city: development strategy, institutions and business environment", Cities, 20(2) 115-127.

Simmie, J., (2004) "Innovation and clustering in the globalised international economy", Urban Studies, Vol. 41, Nos. 5/6, May, pp. 1095-1112.

Smith, S. J. and Ford, J. (2002) Home-ownership: flexible and sustainable? Housing Finance 55: 35-52.

Troutman, P. (2004) "A Growth Machine's Plan B: Legitimating Development When the Value-free Growth Ideology is Under Fire", Journal of Urban Affairs 26(5) 611-622.

Turok, I. (2000) Inclusive Cities: Building Local Capacity for Development, European Commission, Luxembourg. 
Van den Berg, L., Braun, E. and Van der Meer, J. (1997), "The organising capacity of metropolitan region", Environment and Planning C, 15 253-272.

Van der Heijden, K. (1996) Scenario Planning - the art of strategic conversation, Chichester: John Wiley and Sons.

Van der Heijden, K. (2002) 'Can internally generated futures accelerate organizational learning?', Paper for Conference on Probing the Future: Developing Organizational Foresight in the Knowledge Economy, University of Strathclyde.

Wannop, U. (1995) The Regional Imperative: Regional Planning and Governance in Britain, Europe and the United States, Jessica Kingsley, London.

Wood, G. and Parr, J.B. (2005) Transaction costs, agglomeration economies and industrial location, Growth and Change, 36(1) 1-15. 


\section{Scenario Planning for the Edinburgh City Region}

Figures and Tables

\section{Figure 1 GDP Per Capita A sample of European Cities}

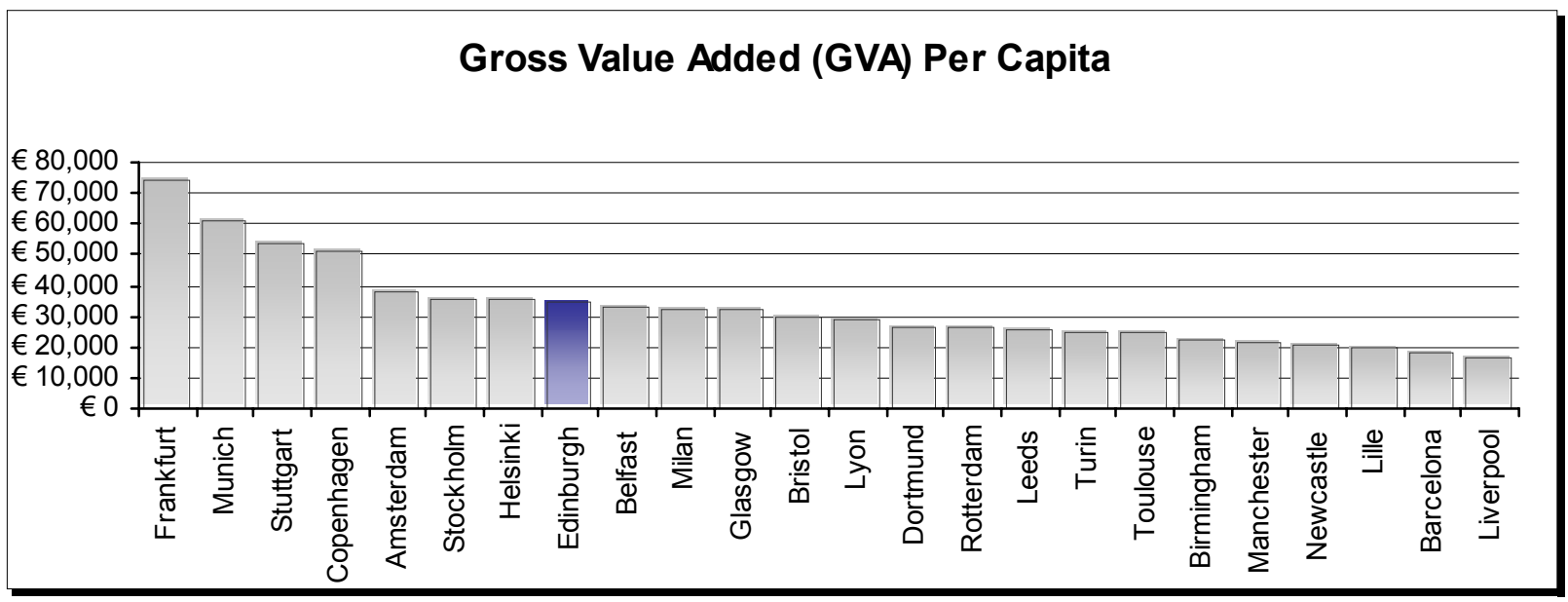

Source: Parkinson et al (2004).

\section{Figure 2 Distribution of the Knowledge Economy in Scotland}

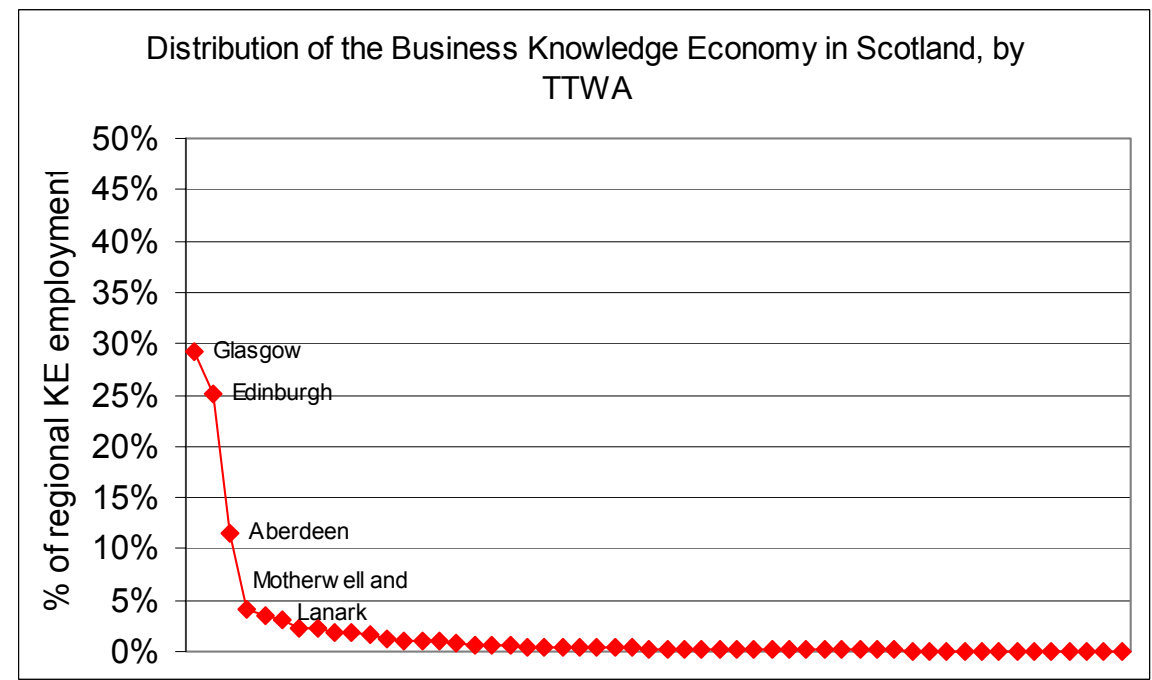

Source: Local Futures Group (2004) 
Figure $3 \quad$ Key issues matrix

Issues importance/uncertainty matrix

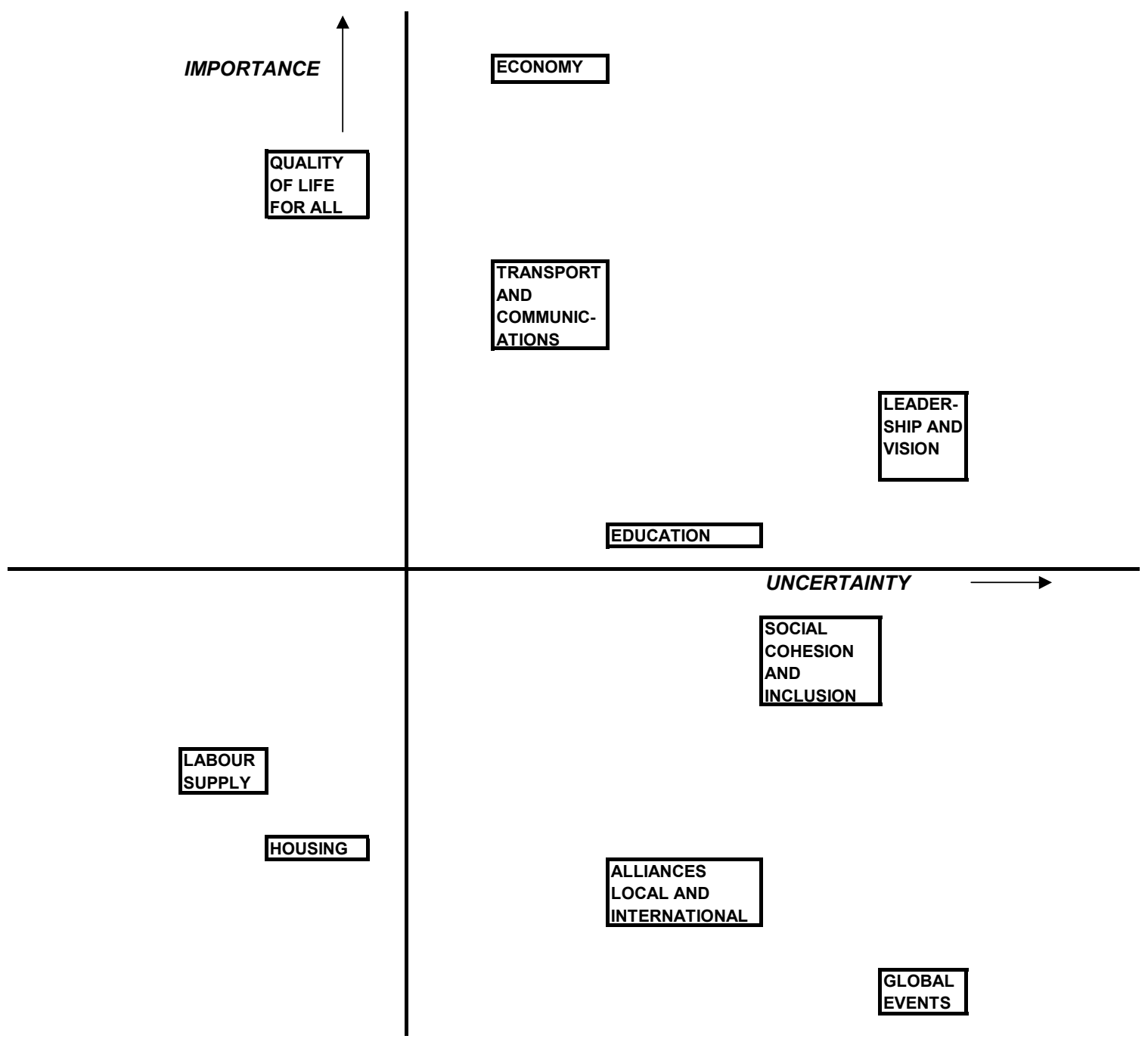


Figure 4 Summary of scenario stories

\section{Capital Gains}

- Boom in financial sector, success in education, bio-technology, tourism and SMEs

- Population growth to over 1 million in the ECR

- De-congestion on roads, charging to fund cheap, efficient public transport throughout ECR

- Desirable quality of life

- Political change of partisan attitudes

- Women in leadership

- New, inclusive political networked alliances

- Common bold vision for the ECR and Scottish central belt

- Great pride in the capital

- $\quad$ Big events (e.g., major games)

- Feel good factor

- City involved heavily in EU and key economic sectors of Europe

- Immigrants welcomed

\section{Capital Punishment}

- Cushioned decline of ECR as old money runs dry

- Deteriorating quality of life e.g., expensive housing, poor education

- Conservative views dominate e.g., "Edinburgh is big enough"

- Grid lock, no charging and poor public transport

- Housing e.g., high prices and lack of social housing drive out social mix

- Disjointed and timid vision

- Infrastructural decay e.g., historic loss of 'world heritage status'

- Business detached from City

- Government spending continues to be directed to the west of Scotland to the detriment of ECR

- Exodus of head offices e.g., HBOS

- Feel bad factor

- 'Desolation Row!' 


\section{Table 1: Annual GVA Growth Rates 1999-2003}

$\begin{array}{ll}\text { Edinburgh } & 5.2 \% \\ \text { Scotland } & 2.2 \% \\ \text { UK } & 2.3 \%\end{array}$

Source: Oxford Economic Forecasting (2004).

Table 2: Ranking of key issues facing Edinburgh city region

$\begin{array}{llll}1 & \text { Economy } & 6 & \text { Social Cohesion and Inclusion } \\ 2 & \text { Quality of Life } & 7 & \text { Labour Supply } \\ 3 & \text { Transport and Communications } & 8 & \text { Housing } \\ 4 & \text { Leadership and Vision } & 9 & \text { Alliances } \\ 5 & \text { Education } & 10 & \text { Global Events }\end{array}$

Source: ECR scenarios working group.

In 2003, strategists in the City of Edinburgh Council and its leading partner organisations turned to scenario planning to help develop a robust, confident vision for the city region's economic future. An influential steering group, representing most walks of life in the city and its region, managed a project running through 7 stages from scoping, data collection, generation of key issues, investigation of these key issues, scenario building and scenario testing to the final analysis of scenario implications for 
policy and strategy. A strong social science methodology underwrote the data collection and analysis while active facilitation of the process maintained momentum.

Two robust and creative scenarios emerged form the process, 'Capital Punishment' and 'Capital Gains'. The former denoted slow relative growth, with the gradual exodus of key finance and business services firms, the attainment and continuation of gridlock, house prices accelerating beyond the reach of key workers and an eventual, inevitable decline cushioned by old money and tourism. The latter was more ambitious, with a growth in education, biotechnology and tourism combined with a continued, enhanced global financial services presence. Robust traffic management, supported by the introduction of congestion charging and the construction of a new tramway network and heavy rail links including one to the airport, made daily commuting and business interaction easier. Hallmark events focused minds on the continuous need to refurbish, invent and innovate over the long term.

The scenarios were well received and after substantive public debate, the original steering group met again to consider their impact on immediate policy and to debate appropriate responses to the critical strategic question for the city region: how could Edinburgh and its Region defend against capital punishment and drive forward to achieve the capital gains? 